\title{
Repetitive Transcranial Magnetic Stimulation in the Treatment of Chronic Orofacial Pain
}

\author{
J. FRICOVÁ ${ }^{1}$, M. KLÍROVÁ ${ }^{2}$, V. MASOPUST ${ }^{4}$, T. NOVÁK ${ }^{2}$, K. VÉREBOVÁ ${ }^{2}$, \\ R. ROKYTA ${ }^{3}$
}

${ }^{1}$ Pain Management Center, Department of Anesthesiology and Intensive Care Medicine, First Faculty of Medicine and General University Hospital, Charles University in Prague, Prague, ${ }^{2}$ Psychiatric Center, Third Faculty of Medicine, Charles University in Prague, Prague, ${ }^{3}$ Department of Normal, Pathological and Clinical Physiology, Third Faculty of Medicine, Charles University in Prague, Prague, ${ }^{4}$ Department of Neurosurgery, Military Faculty Hospital, Charles University in Prague, Prague, Czech Republic

Received March 16, 2013

Accepted May 24, 2013

\section{Summary}

Repetitive transcranial magnetic stimulation (rTMS) is noninvasive neuromodulation method. We applied rTMS for the treatment of farmacoresistant chronic orofacial pain. We compared the effect of $10 \mathrm{~Hz}$ and $20 \mathrm{~Hz}$ stimulation. The study included 23 patients for $20 \mathrm{~Hz}$ stimulation and 36 patients for $10 \mathrm{~Hz}$ stimulation with pharmacotherapy resistant chronic facial pain aged 33-65 years with pain duration of at least 6 months. Monitoring of treatment effects was performed within 15 minutes of each rTMS application (days 1-5) and finally stimulation (active vs. sham coil). If compared with data with $10 \mathrm{~Hz}$ rTMS study $(n=36)$ and with $20 \mathrm{~Hz}$ rTMS ( $n=23)$ trials using a parallel design. Only the results obtained in a series of five rTMS treatments in the first step (active $n=24$, sham $n=12$ ), that $20 \mathrm{~Hz}$ frequency rTMS using a higher intensity ( $95 \%$ of motor threshold) to be equally effective relative to VAS (Visual analogue scale) and QST (quantitative sensory testing). In conclusions, the better results with the relief of orofacial pain were obtained with $20 \mathrm{~Hz}$ stimulation if compared with $10 \mathrm{~Hz}$ stimulation. It was proved with subjective (VAS) and objective evaluation (QST). rTMS can be used in the treatment of chronic intractable pain.

\section{Key words}

rTMS $10,20 \mathrm{~Hz} \bullet$ Orofacial pain

\section{Corresponding author}

Jitka Fricová, Karlovo Náměstí 32, 12808 Prague 2, Czech Republic. Fax: 00420224966 373. E-mail: j.fricova@seznam.cz

\section{Introduction}

The prevalence of facial pain in the general population was described by Koopman et al. (2009). Causes of orofacial pain include: trigeminal neuralgia, postherpetic neuralgia, cluster headache, occipital neuralgia, local neuralgia, atypical facial pain, glossopharyngeal neuralgia and paroxysmal hemicrania. Peripheral pain mechanisms of orofacial pain are generally similar to other pain located elsewhere in the body. It concerns activation of receptors of sensory neurons, channels and signaling pathways for the transduction and propagation of nociceptive stimuli (Henry and Hargraves 2007, Fregni et al. 2007). Diffuse noxious inhibitory controls (DNIC) are used to explain the pathophysiological mechanism of atypical but not classical trigeminal neuralgia. Atypical trigeminal neuralgia is a rare neuropathic facial pain disorder. DNIC can be triggered using a standard counter-irritation paradigm (i.e., immersion of the arm in painfully cold water) (Leonard et al. 2009). Also orofacial pain with a cardiac origin has been described, these patients describe the pain as non-radiating bilateral mandibular pain (López-López et al. 2012). Wirz et al. (2010) described that chronic orofacial pain lasting more than 6 months was identified in 1,767 patients. $64 \%$ were female, $76 \%$ were between 20 and 59 years old, $66.3 \%$ had changed doctors on multiple occasions, and $29.5 \%$ had psychological comorbidities. The most common causes 
of pain were temporomandibular disorders, atypical odontalgia, and atypical facial pain, which accounted for $83.4 \%$ of the sample, with purported etiologies of surgery or trauma $(52.4 \%)$, musculoskeletal disorders (24.2\%), prosthetics (11.4\%), or psychosomatic causes $(11.7 \%)$. Secondary pain syndromes were found in $25 \%$ of patients. Motor cortex stimulation was used as part of the treatment of intractable facial pain caused by trigeminal nerve pain from the deafferentation following rhizotomy or by deafferentation pain secondary caused by meningioma or postherpetic neuralgia. Esfahani (2011) described the application of motor cortex stimulation on several forms of intractable facial pain. Atypical facial pain can be also treated using upper thoracic dorsal column stimulation. This is based on known effects of spinal cord stimulation for treatment of refractory angina pectoris. The main mechanisms of action of rTMS that leads to pain relief are considered to be: (a) its influence on the reorganization of the homunculus damaged by pain (Borckardt et al. 2007) and (b) the indirect effect on neuronal activity of remote cortical and subcortical structures, causing inhibition of painful sensory information leading to the spinothalamic pathway (Rokyta and Hakl 2011). At present, rTMS is considered to be a very promising method for treatment of chronic pain, although many of the stimulation parameters for pain treatment are still not fully established (Rossini and Rossi 2007, Rollnik et al. 2003). A recent meta-analysis (Leung et al. 2009) demonstrated that the application of the coil is usually targeted on the M1 motor cortex; also noted was that the effectiveness of rTMS, in the treatment of pain, increased with increased stimulation frequency, increased with the number of rTMS applications, and increased with the number of pulses during stimulation.

\section{The aim of the study}

The aim of parallel, double-blind, randomized study was:

1. to demonstrate the effectiveness of $20 \mathrm{~Hz}$ rTMS application (to the contralateral motor cortex of the somatotopic sites corresponding to the location of the pain) in the treatment of patients with chronic orofacial pain syndrome, assessed via subjective evaluation using a visual analogue scale (VAS), objective evaluation using quantitative sensory testing (QST),

2. to compare the effectiveness of treatment relative to placebo rTMS. A double-blind, placebo-controlled trial using a parallel design monitored the ability of rTMS to change the perception of pain intensity and character in the involved area as defined by subjective scales (VAS) and objective assessment instruments, i.e. quantitative sensory testing (QST).

The study evaluated and compared the immediate and delayed effect of high frequency rTMS $(>1 \mathrm{~Hz}$ ) focused on the contralateral motor cortex at the point corresponding to the somatotopic location of pain (Lefaucheur 2006a, b) and compared the results with placebo rTMS, applied using a sham (placebo) coil.

\section{Methods}

\section{Methods of data collection}

We prospectively enrolled total number of 23 patients (16 Females, 7 Males) with pharmacotherapy resistant chronic facial pain (trigeminal neuralgia, atypical orofacial pain, post-herpetic neuralgia, dental pain) aged 33-65 years (mean age $=50.7$ yrs), with pain duration of at least 6 months, while on analgesic medications. Pain medications included: 1 . anticonvulsants or benzodiazepines and hypnotics: pregabalin $(n=4)$, gabapentin $(n=5)$, clonazepam $(n=1)$, bromazepam $(n=1)$, zolpidem $(n=1), 2$ antidepressants: duloxetine $(n=2)$, venlafaxine $(n=3)$, amitriptyline $(n=1) ; 3$. opioids: fentanyl $(n=2)$, dihydrocodeine $(n=1)$, oxycodone $(n=2)$ 4. NSAIDs and muscle relaxants: paracetamol $(\mathrm{n}=2)$, metamizole $(n=1)$, tizanidine $(n=1)$.

From the set of 23 patients studied, 17 had secondary trigeminal neuralgia, 11 of them were linked to stomatosurgical (dental surgery) events, while 6 patients had secondary neuralgia after surgery or neurosurgery on the head. The remaining 6 patients had a diagnosis of atypical orofacial pain without a clear organic substrate. Patients included in the study met the following inclusion criteria: (a) orofacial pain syndrome, intractable pharmacoresistant pain, which was defined as the persistence of pain despite at least two attempts at pharmacological treatment in the past, both of sufficient dose and sufficient time, (b) stable analgesic medication for at least 1 month before the start of the study and throughout its course and during follow-up evaluation two weeks after completion of rTMS, (c) 18-65 years of age, (d) the absence of severe organic brain damage or other serious diseases, which could interfere with rTMS (epilepsy) and the absence of any metallic implants in the body (restrictions similar to those for an MRI).

During the baseline period, patients were informed, in detail, about the nature of the study, the clinical course and treatment effects. All participants 
signed an informed consent, which in its structure and content was fully consistent with the latest version of the Declaration of Helsinki and the study was approved by the local Ethics Committee of the 3rd Faculty of Medicine. As part of the informed consent, patients were informed about possible side effects and possible complications of treatment. Participation in the study was voluntary and without any financial reward. After the initial examination, which included a detailed analysis to determine the type and nature of pain, and on the day prior to starting treatment with rTMS, participants were clinically evaluated using the subjective VAS (Khedr et al. 2005) using a scale of 0 to 10 points ( 0 representing the absence of pain and 10 being maximum pain) and QST, which set the threshold for thermal and tactile (touch) sensation in the affected facial area. Thermal sensation was assessed using a specially modified device that creates increasing irritation using a stream of warm air (the temperature of which ranged between 44 and $55^{\circ} \mathrm{C}$ ). Mechanical sensitivity, specifically, tactile threshold, was determined using von Frey hairs (Touchtest sensory evaluators, North Coast Medical).

After inclusion in the study, patients were randomly divided into one of two treatment branches (active arm, $\mathrm{n}=13$ vs. inactive $\operatorname{arm}$ (sham), $\mathrm{n}=10$ ). Monitoring of treatment effects was performed within 15 minutes of each rTMS application (days 1-5) and finally stimulation (active vs. sham coil).

rTMS stimulation was applied using an aircooled, 70-millimeter coil creating a magnetic field of 1-2 Tesla in a time interval of 100-200 ms using a Magstim Super Rapid stimulator (Magstim, Whitland, United Kingdom). The active group (20 Hz rTMS) received five sessions (applications) continuously during working days (day 1-5). Individual application of rTMS (720 pulses / session) included a 20-36x train of pulses, with an intertrain interval of $1.9 \mathrm{~s}$, using an intensity of $95 \%$ of the motor threshold at intervals of 2 weeks after rTMS treatment (day 21). In all cases, the evaluator was blinded to the type of stimulation (active or shame). Stimulation parameters were chosen based on available data found in published studies, including a previous data from our pilot project, which demonstrated the clinical effect (rated VAS) of serial $10 \mathrm{~Hz}$ stimulation using different stimulus intensities, i.e. $85 \%, 90 \%$ and $95 \%$ of motor threshold, for a total of 600 pulses / session applied over 5 sessions several days apart with rTMS application focused over the contralateral motor cortex at the point corresponding to the somatotopic localization of pain sites. The area was identified using functional sites, which is an adequate and well-reproducible method for stimulating the motor cortex. The motor threshold intensity was set at the lowest intensity of the device, an intensity at which at least 5 of the 10 stimuli were recorded with electromyography and produced a visually detectable response to stimulation of cortical areas representing somatotopic localization of the abductor pollicis brevis (EMG Neurosign 400) $\geq 50$ microvolts. During placebo (sham stimulation), an inactive rTMS was used as a sham coil and was placed in the identical area as the active coil. During sham rTMS stimulation, patients recorded identical experiences (including sound effects, somatic sensations caused by contraction of the muscles of the scalp) as during active stimulation. The direct effect of the magnetic field on the cerebral cortex, however, had minimal effect (Kleinjung et al. 2008).

\section{Statistical analysis}

Baseline demographic and clinical characteristics for both groups at baseline and between treatment groups were compared using the unpaired t-test or Mann-Whitney U test for continuous variables and the $\chi^{2}$ test or Fisher exact test for categorical variables. Pain levels were assessed at baseline, after each rTMS session and two weeks (2W) after the last session using the VAS and QST. The least square (LS) QST mean changes (with $95 \% \mathrm{CI}$ ) from baseline to the final rTMS on day 5 and to the end of follow-up on day 21 were compared between groups using the Mann-Whitney U test. Subsequently, the measurement values from each loop (seven time points) were analyzed using repeated analysis of variance measures (RM-ANOVA) and the Greenhouse-Geisser correction for non-sphericity followed by the Bonferroni's multiple comparison post-hoc test. All statistical analyses were performed using Statistica 9.0 (Statsoft, Inc., Tulsa, USA). For the measurement of rTMS effect were used subjective and objective evaluation. For the subjective evaluation the visual analogue scale (VAS) was used. For the objective evaluation the methods of quantitative sensory testing (QST) were used. There were measured or thermical threshold or mechanical pressure threshold (von Frey hairs). The measurements were effectuated after each stimulation. 

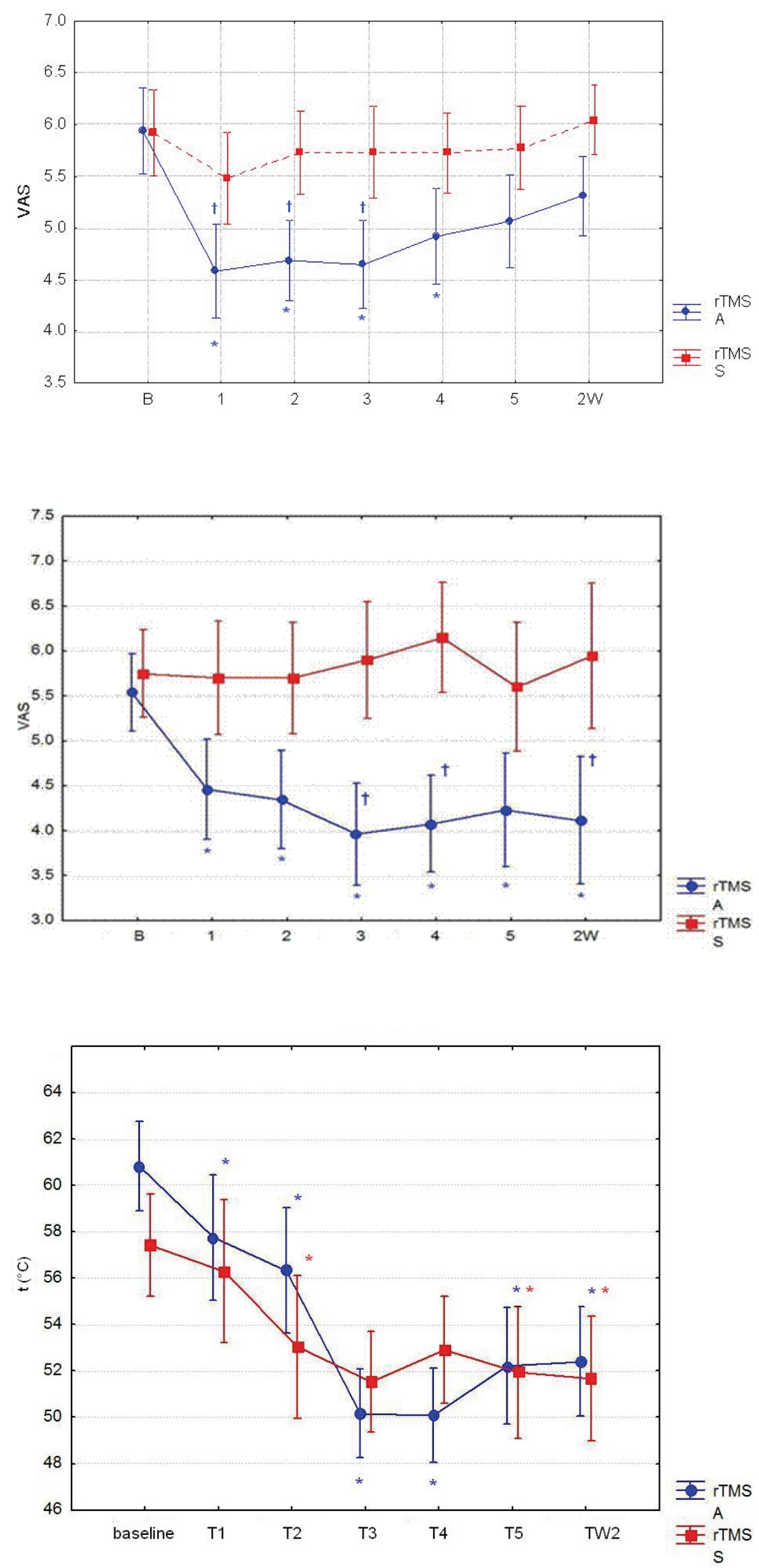

Fig. 1. The clinical effect of $10 \mathrm{~Hz}$ rTMS in Visual analog scale comparing active rTMS and sham rTMS $(\mathrm{N}=36)$. Data are presented as mean. rTMS repetitive Transcranial Magnetic Stimulation, A - Active, S - Sham, VAS - Visual Analog Scale of Pain Intensity, B - VAS Baseline, 1-5 - VAS after rTMS 1-5, VAS $2 \mathrm{~W}$ - VAS after 2 weeks after the end of rTMS. $+p \leq 0.05$ intergroup comparison, $* p \leq 0.05$ intragroup comparison. ANOVA: $F 6,204=2.28 ; p=0.038$

Fig. 2. The clinical effect of $20 \mathrm{~Hz}$ rTMS in Visual analog scale comparing active rTMS and sham rTMS $(\mathrm{N}=23)$. Data are presented as mean. rTMS repetitive Transcranial Magnetic Stimulation, A - Active, S - Sham, VAS - Visual Analog Scale of Pain Intensity, B - Baseline, 1-5 - VAS after rTMS 1-5, 2W - VAS after 2 weeks after the end of rTMS. $+p \leq 0.05$ intergroup comparison, $* p \leq 0.05$ intragroup comparison

Fig. 3. The influence of $20 \mathrm{~Hz}$ rTMS on thermic treshold changes in Quantitative sensory Testing comparing active rTMS and sham rTMS $(\mathrm{N}=23)$. Data are presented as mean. rTMS - repetitive Transcranial Magnetic Stimulation, A - Active, S Sham, $\mathrm{t}\left({ }^{\circ} \mathrm{C}\right)$-Temperature evaluated in Celsium degrees, baseline - thermic threshold at baseline, T1-5 - thermic threshold after rTMS 1-5, TW2 thermic threshold after 2 weeks after the end of rTMS. $+p \leq 0.05$ intergroup comparison, $* \mathrm{p} \leq 0.05$ intragroup comparison 

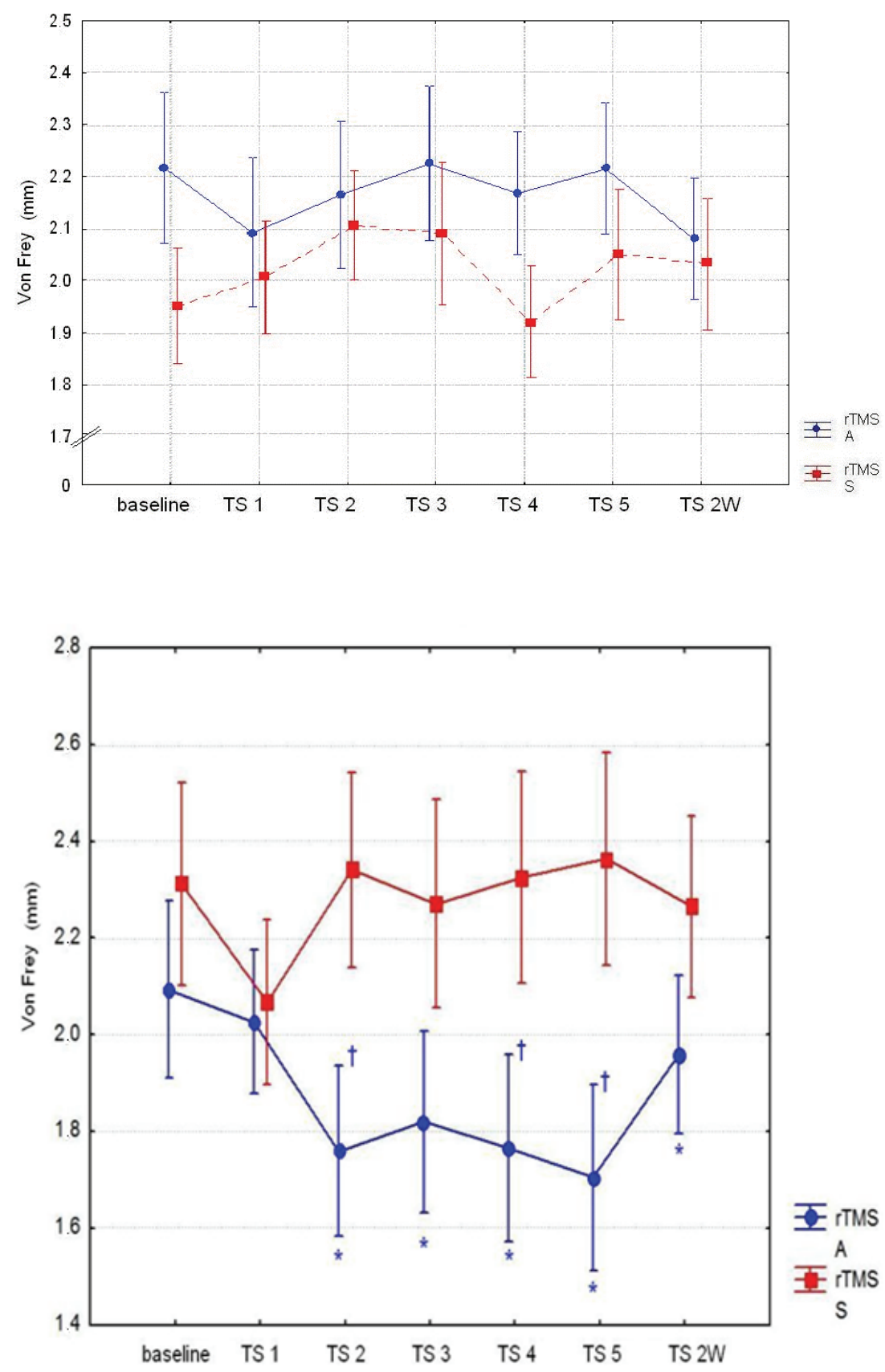

Fig. 4. The influence of $10 \mathrm{~Hz}$ rTMS on tactile sensation in Quantitative sensory Testing measured by von Frey filament comparing active and sham rTMS $(\mathrm{N}=36)$. Data are presented as mean. rTMS - repetitive Transcranial Magnetic Stimulation, A - Active, S Sham, mm - millimeters, baseline threshold of tactile sensation at baseline, TS 1-5 - threshold of tactile sensation after rTMS 1-5, TS 2W threshold of tactile sensation 2 weeks after the end of rTMS. $+p \leq 0.05$ intergroup comparison, $* p \leq 0.05$ intragroup comparison. ANOVA: $F 6,204=0.251 ; p=0.958$
Fig. 5. The influence of $20 \mathrm{~Hz}$ rTMS on tactile sensation in Quantitative sensory Testing measured by von Frey filament comparing active rTMS and sham rTMS $(\mathrm{N}=23)$. Data are presented as mean. rTMS - repetitive Transcranial Magnetic Stimulation, A Active, S - Sham, mm - millimeters, baseline - threshold of tactile sensation at baseline, TS 1-5 threshold of tactile sensation after rTMS 1-5, TS 2W - threshold of tactile sensation 2 weeks after the end of rTMS. $\dagger p \leq 0.05$ intergroup comparison, $* p \leq 0.05$ intragroup comparison

\section{Results}

It can be concluded:

1) The real stimulation is more effective than the shame stimulation (Fig. 1, 2, 5).

2) The results from thermic stimulation have no significant difference between real and shame stimulation. In both cases $(10,20 \mathrm{~Hz})$ there are the decreasing of the effect after third stimulation which lasts up to 14 days (Fig. 3).
3) $20 \mathrm{~Hz}$ stimulation has significantly stronger effect than $10 \mathrm{~Hz}$ stimulation (Fig. 4) which is not sufficiently strong to have the real effect. $20 \mathrm{~Hz}$ stimulation during five days has very strong antinociceptive effect. This effect is stabilized only after $20 \mathrm{~Hz}$ stimulation after 14 days (Fig. 1, 2, 5).

4) The effects are clearly expressed in VAS evaluation (Fig. 1, 2) and in tactile (von Frey) measurements (Fig. 5) but there is no significant difference in the QST measurement of thermic stimulation (Fig. 3). 


\section{Discussion}

The use of rTMS in the treatment of chronic intractable pain is reserved for pain that does not respond to analgesics and for pain in which the cause is difficult to remove. If it can be demonstrated to have an analgesic effect, then rTMS could be considered for inclusion in the current methods of pain treatment (Rokyta and Fricová 2012). The advantage of magnetic stimulation is that it is a non-invasive procedure that is not time-consuming. Before rTMS can be routinely used in the treatment of chronic pain, it is necessary to accurately determine the amount and duration for each stimulation session, thereby ensuring the optimal duration of effect. From our results it is possible to conclude that the more effective rTMS was obtained with $20 \mathrm{~Hz}$ stimulation if compared with our results with $10 \mathrm{~Hz}$ stimulation in our previous pilot study (Fricová et al. 2009). These results were measured with subjective evaluation of the pain, VAS, and with objective measurement using QTS. In objective evaluation the tactile measurement proved to be more important, while the results from measurement of thermal thresholds were not significant. The two treatment groups (active vs. sham) were comparable with respect to baseline demographic and clinical characteristics. rTMS was well tolerated, and no serious adverse effects were reported. In our study we combined both sham or real stimulation. Another advantage over other neuromodulatory methods is the price of the equipment. It has been included among the EFNS (European Federation of Neurological Societies) guidelines for Neurostimulation therapy (Gruccu et al. 2007).

rTMS has also been tested on healthy subjects and was found to cause facilitation of motor evoked potentials (Gilio et al. 2009), leading to an alternative interpretation of the effects of rTMS, which involves the activation of plasticity in the cerebral cortex (Ziemann 2004). Another possible pathophysiological explanation is that lowfrequency stimulation $(1 \mathrm{~Hz})$ reduces the activity of excitatory circuits in the human motor cortex (Di Lazzaro et al. 2008). Our results did not completely confirm this hypothesis. rTMS has also been investigated in depression, Parkinson's disease, spinocerebellar degeneration, epilepsy, urinary incontinence, movement disorders, chronic pain, migraines and chronic tinnitus (Kleinjung et al. 2008, Hausmann et al. 2004). The method did very well in comparison with epidural motor cortex stimulation and transcranial direct current electrical stimulation both in terms of effect and having a favorable cost / effectiveness ratio (Zaghi et al. 2009). rTMS has also been tested in monkeys (Ugawa et al. 2006). Effectiveness of rTMS also depends on the type of neuropathic pain (Leung et al. 2009, Lefaucheur 2006a, b).

Application of rTMS induces not only subjective pain relief (Hirayama et al. 2006, Leung et al. 2009 Lefaucheur 2006a, b) but also objective changes in Quantitative Sensory Testing (QST), namely changes in thermal threshold (Borckardt et al. 2007, Lefaucheur et al. 2008) and the threshold for tactile sensation (Summers et al. 2004, Lefaucheur et al. 2008). Changes in the threshold of tactile sensation can be easily and reliably accessed with techniques using von Frey monofilaments and a Peltier thermal generator can be used to determine changes in thermal threshold (Lefaucheur et al. 2008).

Information regarding the prevalence of orofacial pain varies considerably from study to study and depends on the source of pain, however, it appears to affect between 10 to $50 \%$ of the adult population. The most common cause of facial pain is pain of dental origin, which begins after dental reparation or dental surgeries. Very often it is an intractable pain and pharmacological treatment is unsuccessful. Recent studies have suggested the involvement of the peripheral and central nervous system in the pathophysiology of atypical odontalgia.

Today rTMS is used with short-term success in the treatment of pain, mostly neuropathic pain. Previous studies have confirmed the ability of high $(>1 \mathrm{~Hz})$ rTMS to stimulate the M1 (Hirayama et al. 2006, Johnson et al. 2006) in the treatment of facial pain. Valmunen et al. (2009) have shown that the application of rTMS to the M1 changes the thermal pain threshold in this and related areas. Also of interest is the DLPFC (dorsolateral prefrontal cortex) coil position, which seems to have a substantial influence on neuronal circuits involved in the processing of cognitive and emotional aspects of pain.

\section{Other effects of rTMS on pain}

$1 \mathrm{~Hz}$ (low frequency) rTMS reduces acute pain induced by capsaicin temporarily improves phantom pain (Töpper et al. 2003) and reduces pain in fibromyalgia (Sampson et al. 2006). High-frequency rTMS (>1 Hz) has been shown to produce changes in the pain threshold in people with chronic pain (Johnson et al. 2006). Higher frequency rTMS $(5-10 \mathrm{~Hz})$ also reduces deafferentation intractable pain in spinal cord injury and in peripheral nerves (Saitoh et al. 2007). We enlarged these indications of high frequency stimulation $(>1 \mathrm{~Hz}$ ) by using $20 \mathrm{~Hz}$ stimulation, which was found to be very suitable for 
treatment of orofacial pain.

rTMS suppresses the perception of painful CRPS (Complex Regional Pain Syndrome) (Pleger et al. 2004, Picarelli et al. 2010), and suppresses neuropathic pain, in particular pain with a central origin (Leung et al. 2009). rTMS is also effective in treating migraines with or without aura (Conte et al. 2010, Brighina et al. 2005). Low-frequency vertex rTMS $(1 \mathrm{~Hz})$ has been shown to have a prophylactic effect on migraines (Teepker et al. 2010).

Our study confirmed that rTMS at a frequency of $20 \mathrm{~Hz}$, functionally localized to the area of the motor cortex contralateral to the position corresponding to the somatotopic location of the pain source is effective in the treatment of chronic orofacial pain. Subjective evaluation of intra-and inter-group VAS scores, compared with the control group, showed both immediate and delayed treatment effects in subsequent measurements. The results of the VAS ratings are consistent with results of previous studies (Lefaucheur et al. 2001, Pleger et al. 2004, Johnson et al. 2006). Changes in thermal sensation were not statistically different between groups. Intragroup comparison confirmed the reduction of thermal threshold for hot air stimulation after repeated rTMS application. Some studies have confirmed the influence of rTMS to reduce the threshold for thermal stimulation of both cold air (Johnson et al. 2006) and hot air (Lefaucheur et al. 2008). Other studies however, have shown an increased thermal threshold for hot air stimulation after rTMS (Johnson et al. 2006). Inter-group comparisons of tactile sensations showed acute effects after repeated stimulation (days 2, 4 and 5) but not when measured using a longer interval (day 21). Confirmation of the influence of rTMS on QST, specifically its ability to reduce the threshold for tactile (mechanical) sensation, supports the hypothesis that modulation of tactile and thermal perception in the painful zone interacts with the analgesic effect of cortical stimulation (Lefaucheur et al. 2008).

Our data are consistent with previous studies which reported that the use of a higher frequency increased number of pulses during an rTMS application and an increased number of applications) (Leung et al. 2009) led to increased efficacy of the method in the treatment of pain. The best frequency of stimulation for the most effective pain treatment has not yet been resolved. Our results support the effect of $20 \mathrm{~Hz}$ rTMS.

\section{Complications of rTMS}

Low frequency rTMS stimulation can cause nausea, probably via stimulation of the posterior cranial fossa (Satow et al. 2002). rTMS of the premotor cortex reduces painful axial spasms in generalized secondary dystonia (Lefaucheur et al. 2004). rTMS can also have side effects and randomly caused convulsions in control patients, one patient was reported to suffer from depression and parietal epilepsy (Rosa et al. 2006). Side effects include induction of epileptic seizures (less than $1 \%$ of patients), which is more likely in high-frequency rTMS $(>1 \mathrm{~Hz})$ and rarely occurs in low-frequency rTMS $(\leq 1 \mathrm{~Hz})$. A more common problem is the formation of transient pain, which is precisely located and depends on the site of stimulation (Rossi et al. 2009).

\section{Conclusions}

rTMS is very useful noninvasive neuromodulation treatment of chronic orofacial pain. We can recommend to use higher stimulatory frequency $(20 \mathrm{~Hz})$ than the $10 \mathrm{~Hz}$ stimulation.

For rTMS to be routinely used in the treatment of chronic pain, it is necessary to accurately determine the amount and duration of each stimulation, thereby ensuring the optimal efficacy of the method. rTMS is a non-invasive method of neuromodulation, which represents a major breakthrough in neurosurgical approaches to the treatment of pain (Khedr et al. 2005, Johnson et al. 2006).

The method is included among the EFNS (European Federation of Neurological Societies) guidelines for neurostimulation therapy (Cruccu et al. 2007). For treatment of pain that is unresponsive to analgesics and for pain in which the cause of the pain is difficult to remove. If the analgesic effect rTMS can be demonstrated, it could be considered among current methods for pain treatment.

\section{Conflict of Interest}

There is no conflict of interest.

\section{Acknowledgements}

The study was supported by the project of Charles University PRVOUK P34, by grant of the Ministry of Health - IGA NT 14484-3/2013. 


\section{References}

AHDAB R, AYACHE SS, BRUGIÈRES P, GOUJON C, LEFAUCHEUR JP: Comparison of „standard“ and „navigated“ procedures of TMS coil positioning over motor, premotor and prefrontal targets in patients with chronic pain and depression. Neurophysiol Clin 40: 27-36, 2010.

BORCKARDT JJ, SMITH AR, REEVES ST, WEINSTEIN M, KOZEL FA, NAHAS Z, SHELLEY N, BRANHAM RK, THOMAS KJ, GEORGE MS: Fifteen minutes of left prefrontal repetitive transcranial magnetic stimulation acutely increases thermal pain thresholds in healthy adults. Pain Res Manag 12: 287-290, 2007.

BRIGHINA F, GIGLIA G, SCALIA S, FRANCOLINI M, PALERMO A, FIERRO B: Facilitatory effects of $1 \mathrm{~Hz}$ rTMS in motor cortex of patients affected by migraine with aura. Exp Brain Res 161: 34-38, 2005.

CONTE A, BARBANTI P, FRASCA V, IACOVELLI E, GABRIELE M, GIACOMELLI E, AURILIA C, PICHIORRI F, GILIO F, INGHILLERI M: Differences in short-term primary motor cortex synaptic potentiation as assessed by repetitive transcranial magnetic stimulation in migraine patients with and without aura. Pain 148: 43-48. 2010.

CRUCCU G, AZIZ TZ, GARCIA-LARREA L, HANSSON P, JENSEN TS, LEFAUCHEUR JP, SIMPSON BA, TAYLOR RS: EFNS guidelines on neurostimulation therapy for neuropathic pain. Eur J Neurol 14: 952-970, 2007.

Di LAZZARO V, PILATO F, DILEONE M, PROFICE P, OLIVIERO A, MAZZONE P, INSOLA A, RANIERI F, TONALI PA, ROTHWELL JC: Low-frequency repetitive transcranial magnetic stimulation suppresses specific excitatory circuits in the human motor cortex. J Physiol 586: 4481-4487, 2008.

ESFAHANI DR, PISANSKY MT, DAFER RM, ANDERSON DE: Motor cortex stimulation: functional magnetic resonance imaging-localized treatment for three sources of intractable facial pain. J Neurosurg 114: 189-195, 2011.

FREGNI F, FREEDMAN S, PASCUAL-LEONE A: Recent advances in the treatment of chronic pain with noninvasive brain stimulation techniques. Lancet Neurol 6: 188-191, 2007.

FRICOVÁ J, KLÍROVÁ M, ŠOŠ P, TIŠLEROVÁ B, HAECKEL M, MASOPUST V, NOVÁK T, ROKYTA R: Repetitive transcranial stimulation in chronic orofacial neurogenic pain treatment. Congress on Pain, WIP, New York, 2009.

GILIO F, IACOVELli E, FRASCA V, GABRIELE M, GIACOMELli E, De LENA C, CIPRIANI AM, INGHILLERI M: Electrical and magnetic repetitive transcranial stimulation of the primary motor cortex in healthy subjects. Neurosci Lett 455: 1-3, 2009.

HAUSMANN A, KEMMLER G, WALPOTH M, MECHTCHERIAKOV S, KRAMER-REINSTADLER K, LECHNER T, WALCH T, DEISENHAMMER EA, KOFLER M, RUPP CI, HINTERHUBER H, CONCA A: No benefit derived from repetitive transcranial magnetic stimulation in depression: a prospective, single centre, randomised, double blind, sham controlled "add on" trial. J Neurol Neurosurg Psychiatry 75: 320-322, 2004.

HENRY MA, HARGREAVES KM: Peripheral mechanisms of odontogenic pain. Dent Clin North Am 51: 19-44, 2007.

HIRAYAMA A, SAITOH Y, KISHIMA H, SHIMOKAWA T, OSHINO S, HIRATA M, KATO A, YOSHIMINE T:

Reduction of intractable deafferentation pain by navigation-guided repetitive transcranial magnetic stimulation of the primary motor cortex. Pain 122: 22-27, 2006.

JOHNSON S, SUMMERS J, PRIDMORE S: Changes to somatosensory detection and pain thresholds following high frequency repetitive TMS of the motor cortex in individuals suffering from chronic pain. Pain 123: 187-192, 2006.

KHEDR EM, KOTB H, KAMEL NF, AHMED MA, SADEK R, ROTHWELL JC: Longlasting antalgic effects of daily sessions of repetitive transcranial magnetic stimulation in central and peripheral neuropathic pain. $J$ Neurol Neurosurg Psychiatry 76: 833-838, 2005.

KLEINJUNG T, VIELSMEIER V, LANDGREBE M, HAJAK G, LANGGUTH B: Transcranial magnetic stimulation: a new diagnostic and therapeutic tool for tinnitus patiens. Int Tinnitus $J$ 14: 112-118, 2008.

KOOPMAN JS, DIELEMAN JP, HUYGEN FJ, DE MOS M, MARTIN CG, STURKENBOOM MC: Incidence of facial pain in the general population. Pain 147: 122-127, 2009.

LEFAUCHEUR JP: Myoclonus and transcranial magnetic stimulation. Neurophysiol Clin 36: 293-297, 2006a. 
LEFAUCHEUR JP: Stroke recovery can be enhanced by using repetitive transcranial magnetic stimulation (rTMS). Neurophysiol Clin 36: 105-115, $2006 \mathrm{~b}$.

LEFAUCHEUR JP: Principles of therapeutic use of transcranial and epidural cortical stimulation. Clin Neurophysiol 119: 2179-2184, 2008.

LEFAUCHEUR JP, DROBOT X, KARAVEL Y, NGUYEN JP: Pain relief induced by repetitive transcranial magnetic stimulation of precentral cortex. Neuroreport 4: 2963-2965, 2001.

LEFAUCHEUR JP, FÉNELON G, MÉNARD-LEFAUCHEUR I, WENDLING S, NGUYEN JP: Low-frequency repetitive TMS of premotor cortex can reduce painful axial spasms in generalized secondary dystonia: a pilot study of three patients. Neurophysiol Clin 34: 141-145, 2004.

LEFAUCHEUR JP, DROUOT X, MÉNARD-LEFAUCHEUR I, KERAVEL Y, NGUYEN JP: Motor cortex rTMS in chronic neuropathic pain: pain relief is associated with thermal sensory perception improvement. $J$ Neurol Neurosurg Psychiatry 79: 1044-1049, 2008.

LEONARD G, GOFFAUX P, MATHIEU D, BLANCHARD J, KENNY B, MARCHAND S: Evidence of descending inhibition deficits in atypical but not classical trigeminal neuralgia. Pain 15: 217-223, 2009.

LEUNG A, DONOHUE M, XU R, LEE R, LEFAUCHEUR JP, KHEDR EM, SAITOH Y, ANDRÉ-OBADIA N, ROLLNIK J, WALLACE M, CHEN R: rTMS for suppressing neurophatic pain: a meta-analysis. J Pain 10: 1205-1216, 2009.

LÓPEZ-LÓPEZ J, ADSERIAS-GARRIGA MJ, GARCIA-VICENTE L, JANÉ-SALAS E, CHIMENOS-KÜSTNER E, PEREFERRER-KLEINER D: Orofacial pain of cardiac origin, serial of clinical cases. Med Oral Patol Oral Cir Bucal 17: 633-637, 2012.

PICARELLI H, TEIXEIRA MJ, DE ANDRADE DC, MYCZKOWSKI ML, LUVISOTTO TB, YENG LT, FONOFF ET, PRIDMORE S, MARCOLIN MA: Repetitive transcranial magnetic stimulation is efficacious as an add-on to pharmacological therapy in complex regional pain syndrome (CRPS) type I. J Pain 11: 1203-1210, 2010.

PLEGER B, JANSSEN F, SCHWENKREIS P, VÖLKER B, MAIER C, TEGENTHOFF M: Repetitive transcranial magnetic stimulation of the motor cortex attenuates pain perception in complex regional pain syndrome type I. Neurosci Lett 356: 87-90, 2004.

ROKYTA R, FRICOVÁ J: Neurostimulation methods in the treatment of chronic pain. Physiol Res 61 (Suppl 2): S23S31, 2012.

ROKYTA R, HAKL M: Neuromodulation. In: The Treatment of Pain. M HAKL (ed) (in Czech), Mladá fronta, Prague, 2011, pp 89-101.

ROLLNIK JD, DÄUPER J, WÜSTEFELD S, MANSOURI S, KARST M, FINK M, KOSSEV A, DENGLER R: Repetitive magnetic stimulation for the treatment of chronic pain conditions. Suppl Clin Neurophysiol 56: 390393, 2003.

ROSA MA, PICARELLI H, TEIXEIRA MJ, ROSA MO, MARCOLIN MA: Accidental seizure with repetitive transcranial magnetic stimulation. $J$ ECT 22: 265-266, 2006.

ROSSINI PM, ROSSI S: Transcranial magnetic stimulation: diagnostic, therapeutic, and research potential. Neurology 68: 484-488, 2007.

SAITOH Y, HIRAYAMA A, KISHIMA H, SHIMOKAWA T, OSHINO S, HIRATA M, TANI N, KATO A, YOSHIMINE T: Reduction of intractable deafferentation pain due to spinal cord or peripheral lesion by highfrequency repetitive transcranial magnetic stimulation of the primary motor cortex. $J$ Neurosurg 107: 555-559, 2007.

SAMPSON SM, ROME JD, RUMMANS TA: Slow-frequency rTMS reduces fibromyalgia pain: Pain Med 7: 115-118, 2006.

SATOW T, MIMA T, HARA H, OGA T, IKEDA A, HASHIMOTO N, SHIBASAKI H: Nausea as a complication of low-frequency repetitive transcranial magnetic stimulation of the posterior fossa. Clin Neurophysiol 113: 1441$1443,2002$.

TEEPKER M, HÖTZEL J, TIMMESFELD N, REIS J, MYLIUS V, HAAG A, OERTEL WH, ROSENOW F, SCHEPELMANN K: Low-frequency rTMS of the vertex in the prophylactic treatment of migraine. Cephalalgia 30: 137-144, 2010. 
TÖPPER R, FOLTYS H, MISTER IG, SPARING R, BOROOJERDI B: Repetitive transcranial magnetic stimulation of the parietal cortex transiently ameliorates phantom limb pain-like syndrome: Clin Neurophysiol 114: 1521$1530,2003$.

UGAWA Y, OKABE S, HAYASHI T, OHNISHI T, NONAKA Y: Repetitive transcranial magnetic stimulation (rTMS) in monkeys. Suppl Clin Neurophysiol 59: 173-181, 2006.

WIRZ S, ELLERKMANN RK, BUECHELER M, PUTENSEN C, NADSTAWEK J, WARTENBERG HC: Management of chronic orofacial pain: a survey of general dentists in German university hospitals. Pain Med 11: 416-424, 2010.

ZAGHI S, HEINE N, FREGNI F: Brain stimulation for the treatment of pain: a review of costs, clinical effects, and mechanisms of treatment for three different central neuromodulatory approaches. J Pain Manag 2: 339-352, 2009.

ZIEMANN U: TMS induced plasticity in human cortex. Rev Neurosci 15: 253-266, 2004. 